\title{
Maintaining AACSB international accreditation: from basics to best practices
}

From basics to

Faye S. McIntyre

Richards College of Business, University of West Georgia, Carrollton, Georgia, USA, and

Faye W. Gilbert

Maine Business School, University of Maine, Orono, Maine, USA

\begin{abstract}
Purpose - A truly successful continuous improvement review (CIR) visit does more than merely check the boxes for a positive recommendation. It builds the story of the school and should be an opportunity for its culture to shine through. The purpose of this paper is to demonstrate how to facilitate a successful CIR visit by moving from the basics of accreditation to understanding, implementing and "living" best practices.

Design/methodology/approach - Short tenure and high turnover among business school deans, mean that the majority of those leading the CIR may have no previous experience with the process.

Findings - This study begins by providing an overview of the role of accreditation and the role of the dean in the accreditation process. With a combined experience of over 35 years in the dean role and having served on or chaired over 35 accreditation visits, the authors share their experiences and offer a seven-step process for understanding and implementing best practices in the Association to Advance Collegiate Schools of Business accreditation process.
\end{abstract}

Originality/value - The suggestions offered in this study should help schools enhance long-term positive outcomes and serve as a guide to those navigating the CIR process.

Keywords Business schools, Accreditation, Deans, AACSB international, Continuous improvement review

Paper type Viewpoint

\section{Introduction}

Once a college of business has achieved Association to Advance Collegiate Schools of Business (AACSB) International accreditation, the five-year cycle for continuous improvement review (CIR) begins. Unlike initial accreditation visits, the CIR is not a standard-by-standard review. Rather, it is intended to be a wholistic evaluation to assess the quality and continuous improvement in the areas of review (strategic management and innovation, learner success and thought leadership, engagement and societal impact) and centered around the three themes of innovation, engagement and impact (AACSB, 2020a).

(C) Faye S. McIntyre and Faye W. Gilbert. Published in Organization Management Journal. Published by Emerald Publishing Limited. This article is published under the Creative Commons Attribution (CC BY 4.0) licence. Anyone may reproduce, distribute, translate and create derivative works of this article (for both commercial and non-commercial purposes), subject to full attribution to the original publication and authors. The full terms of this licence maybe seen at http://creativecommons.org/ licences/by/4.0/legalcode

Received 9 August 2021 Revised 10 August 2021 Accepted 10 August 2021 
$\mathrm{OMJ}$ 18,5

Managing the CIR process is a key role for the dean; however, short tenure and high turnover among business school deans mean that the majority of those leading the CIR may have no previous experience with the process. AACSB provides training for new deans and various seminars and conferences can provide insight into what goes into the CIR application and report and how to structure the CIR visit. While these resources can lead to a recommendation for maintenance of accreditation, a truly successful CIR visit does more than merely check the boxes for a positive recommendation. It builds the story of the school creating a narrative of its distinctive activities, points of pride and aspirational goals and it should be an opportunity for the culture to shine through. Continuous improvement requires moving from the basics of accreditation to understanding, implementing and "living" best practices. With a combined experience of over 35 years in the dean role and having served on or chaired over 35 accreditation visits, the authors share their experiences in the following pages to help others enhance the long-term positive outcomes from the AACSB accreditation process.

\section{The role of accreditation}

In general, organizations pursue accreditation to increase the quality and value of offerings and to increase their reputation among academic institutions and with the public (Widarsyah et al., 2017). "Accreditation is a procedure by which an authoritative body gives formal recognition that a body or person is competent to carry out specific tasks" (Tomáš, 2017, p. 231). In essence, accreditation affects the program's credibility in the marketplace whether it is in business, medicine, laboratory sciences, engineering or mathematics. When people have limited ways of objectively comparing alternatives, the importance of accreditation is enhanced. A key aspect of the accreditation is in the self-assessment and involvement of constituents in setting goals and enhancing outcomes (Halstead, 2017). Accreditation signals legitimacy and trustworthiness (Desai, 2016). Organizations pursue accreditation to enhance both quality improvement and public accountability (Halstead, 2017).

There are now many options for accreditation of business programs (e.g. AACSB, Association of Collegiate Business Schools and Programs, International Assembly for Collegiate Business Education, European Foundation for Management Development, European Quality Improvement System [EQUIS], Association of MBAs [AMBA]). Each accrediting agency defines standards that promote similar ideals, namely, governance mechanisms, financial sufficiency, faculty qualifications and assurance of learning (Zhao \& Ferran, 2016).

AACSB began to expand internationally in 1995 as it awarded accreditation to its first program outside of North America (Trapnell, 2007). AACSB has progressed from a primarily US institution (and changed its name from "American Association for Colleges \& Schools of Business") to a truly international organization that influences thought leadership and the pursuit of quality outcomes in Taiwan (Chang et al., 2016), Africa (Muuka et al., 2016), the United Kingdom (Cooper et al., 2014), the United Arab Emirates (Goby \& Nickerson, 2014), Pakistan (Shahzad, 2019) and Japan (Suárez-Barraza et al., 2019). While some pursue the triple crown in accreditation (AACSB, EQUIS, AMBA), AACSB is the most recognized and longest standing accrediting body in business education (Smith et al., 2017) and it is cited by many as the leader in international accreditation (Suárez-Barraza et al., 2019; Zhao \& Ferran, 2016).

AACSB accreditation has been shown to add value to the perceived quality of the school, brand recognition and actual improvements in the school (Urgel, 2007). Academic researchers have described the main effects of AACSB accreditation in relation to reputation, leverage for 
change, efficiencies and an enhanced focus on research (Elliott, 2013). In study after study, AACSB accreditation has been cited as a signal of quality education and correlated with effective faculty recruitment and student placement (Miles et al., 2015). AACSB processes and accreditation are associated with such beneficial outcomes as the retention of students, the attraction of faculty, placement in jobs and community perceptions of the institution as a quality provider of business education (Trapnell, 2007). Initial accreditation from AACSB has also been shown to have a profound impact on enrollment and although the growth in enrollment may be of short duration, it differentiates the program from non-accredited counterparts (Womack \& Kruger, 2015). Institutions that achieve accreditation in international contexts benefit from the prestige and signal of quality for the business education provided there (Shahzad, 2019).

There is evidence that strongly suggests AACSB accreditation enhances the value and quality of outcomes for accredited programs (MacKenzie et al., 2019; Trapnell \& Williams, 2012). According to Trapnell and Williams (2012):

AACSB accreditation is earned through a voluntary commitment to enter into a sustained demonstration of quality and continuous improvement by being judged and evaluated against internationally relevant standards. AACSB standards describe attributes of business schools and accounting programs that reflect a blend of inputs (students, sufficiency and qualifications of faculty, physical plant and infrastructure, financial, etc.), processes (curricula management, faculty management, etc.), outputs (graduates, publications, service activities, etc.), and outcomes (qualitative dimensions of outcomes such as student learning achievements, research awards and recognition, etc.) that represent a consensus of factors a quality business school and accounting program should demonstrate. (p. 1072)

AACSB accreditation also includes sharing of information for best practices in business education, access to comparison data and collegial interactions with other deans seeking to improve (Romero, 2008). As described in their study, Miles et al. (2015) found that schools in international locations saw accreditation as essential for global relevance in a competitive environment and as an important criterion for students. Accreditation includes pursuit of excellence and the sustainability of those processes over time (Muuka et al., 2016). The credential is bestowed by a peer-review system that emphasizes a review by colleagues who also implement its standards and shape its frameworks. For programs located in less advanced areas, accreditation is an essential signal of legitimacy (Prasad et al., 2019).

\section{The role of the dean}

The business school dean's position has been recognized as one of the best jobs on a college campus (Bolton, 1997; Burton, 2008; Spritzer, 2004). The dean is the "face" of the school, acknowledged both internally and externally as the leader of the academic unit. A key aspect of this role is leading the accreditation efforts of the school. However, short tenure and high turnover among business school deans mean that the majority of those leading the CIR may have no previous experience with the process and may initially underestimate the power of the accreditation process in building a strong story of the distinctive aspects of the program and its people.

The average tenure for a business school dean at a given institution is relatively short. Wolverton \& Gonzales (2000) reported approximately five years while AACSB $(2015,2018)$ reported average tenure of sitting deans was 4.6 years in 2011-2012, 4.3 years in 2014-2015 and 5.9 years in 2017-2018. As of 2015-2016, 31\% of deans responding to a survey indicated they were in their second (or more) deanship (AACSB, 2016). By 2018, 22.6\% of deans were currently in their second deanship and $10.5 \%$ were in a third or more deanship (Finch \& McIntyre, 2021). 
$\mathrm{OMJ}$ 18,5

For those with previous appointments as dean, familiarity with accreditation standards and processes, connections established through peer review teams (PRT) and existing relationships with AACSB staff members all transfer seamlessly to the new deanship. This political capital and advancement on the accreditation learning curve will benefit both the dean and the business school. However, for roughly two-thirds of business school deans, the CIR visit will be their first (and for many their only) experience in leading the process.

Accreditation is only one of many expectations of deans; duties such as developing internal infrastructures for personnel and budget management, molding and managing the school's culture, external fundraising and advocating for internal resources may be intentionally added to the calendar. Additionally, deans are often held accountable for outcomes such as teaching effectiveness and research productivity over which they have little to no direct influence or control (Gallos, 2002), but these remain central elements to accreditation efforts.

Training by AACSB provides essential information, but it cannot supplant the learning one acquires while preparing for and experiencing a CIR visit, virtually or in person. The following seven-step process is offered to enhance understanding and implementation of best practices, both formal and informal, for the CIR visit. The idea is to build a solid framework for continuous improvements over time.

\section{From basics to best practices}

At a basic level, the AACSB accreditation process ensures the school is engaged in continuous improvements in developing people, processes and programs. Moving beyond the basics includes an understanding of the benefits of working with an international team of deans who may become professional colleagues as all work to make a difference in society. From the application process through the post-visit wrap-up, the cycle of improvement includes an eye toward connecting with others (Figure 1).

\section{Prepare continuous improvement review application and select peer review team}

AACSB clearly outlines expectations for the CIR application, including progress on items identified in the previous CIR process, update on the college's strategic positioning (funds, enrollment, etc.), the scope of the review, commitment to ethics and diversity and a list of comparison groups. Needless to say, double- and triple-checking facts such as degree programs and contact information are essential. For example, previous deans may have overlooked a degree program housed outside the business school that should be submitted for exclusion or changes in the university administration may need to be updated. Getting to know other deans at AACSB and regional associations may help with the identification of peer and aspirant institutions, and thus with ideas of distinctive practices in place in other accredited programs.

Ideally, the application sets the stage for the upcoming CIR report. Thinking through and getting input into key initiatives are opportunities to engage constituents with the accreditation process and to focus on the themes of engagement, innovation and impact. Input and review of drafts by members of the advisory board, upper administration, faculty and students set a tone of inclusion and the team effort at the beginning of developing the report.

Selection of peer and aspirant schools should be a careful and deliberate process as the PRT members may be selected from these groups. Although peer schools should be selected that have enough in common to understand the school's context and challenges, the best peer schools will be those who are peer on multiple criteria rather than just the size of the school as measured by the number of students or number of faculty. Other considerations might include budget and fundraising successes, university structure and positioning, teaching or research focus, the composition of tenured versus untenured or non-tenure track faculty, access to professional staff or adjunct faculty or other factors unique to the school's 


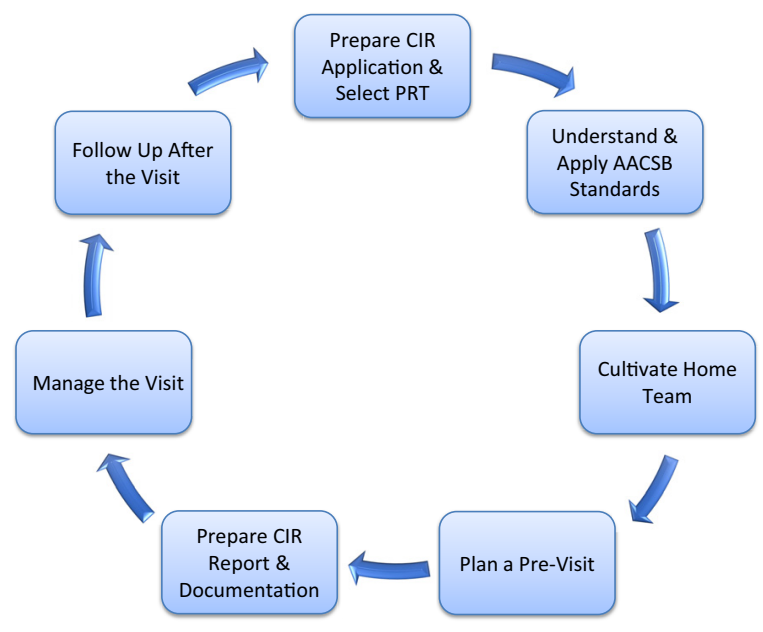

From basics to best practices

203

history or current situation. Including international programs may also provide rich comparison points and new ideas for future growth. Building diversity into the team will help achieve the long-term goal of continuous improvement. The selection of aspirant schools may benefit the school by generating conversations about what the long-term vision should look like.

Viewing the relationship with the school's PRT as a social contract requires more than having peers agree to serve. While the AACSB staff and CIR Committee (CIRC) will propose a team chair to the school, recommendations for "team members beyond the chair will be considered but are not guaranteed” (AACSB, 2019, pp. 5-6). A positive first step is to request permission to list a peer dean as a prospective PRT member before submitting the name to AACSB. This helps build the dean's network and credibility with peers; even if the prospect is not selected for the team, he/she may feel honored to have been asked. Beginning the process with a team member who feels included and honored sets the stage for a positive relationship.

Once the PRT is assigned, generally a year or two prior to the CIR visit, building a relationship with the team members and benchmarking efforts with peer and aspirant programs become beneficial steps. Take the time to meet and greet PRT members at conferences. Share a meal or drink to get to know them (with the school picking up the tab). These informal interactions go beyond the visit itself and can help identify personal commonalities and shared experiences to create long-term friendships that all deans need and use to design improvements in programs.

One final best practice at this stage is to begin building a relationship with the school's AACSB staff liaison. AACSB staff should not be viewed as a contact only when problems arise. An introduction at a conference or emails to check in can create a sense of comradery that may lead to beneficial side conversations or facilitate a difficult conversation later in the process.

\section{Understand and apply Association to Advance Collegiate Schools of Business standards}

Knowing the standards may seem obvious, but this is not a simple step in the CIR process. Clearly articulating which standards (2013 or 2020) the school will be using will have an impact on the report itself and conversations during the visit. While CIR visits are not 
$\mathrm{OMJ}$ 18,5

intended to be a standard-by-standard review, key issues within the standards should be clearly and completely addressed in the report.

Moving to best practices requires thoroughly reading and understanding AACSB's philosophy of accreditation and guiding principles, along with the definitions, the basis for judgment and suggested documentation. The 2020 Interpretative Guidance (AACSB, 2020b) provides valuable insights that can help the school move beyond compliance to apply the true spirit of the standards.

Another valuable resource for understanding the standards and how to apply them is the cadre of dean colleagues who have been through and are going through the same accreditation process. Deans should capitalize on their peers' experience and learning; all deans were new at some point and are generally happy to assist others.

\section{Cultivate home team}

Though the dean is ultimately responsible for leading the accreditation process, the dean cannot manage the CIR visit without input in and assistance from many others. Faculty, administrators, program directors and even board members may be invited to add items that will become part of the CIR report. Asking others to read and edit sections of the report can catch errors, identify additional brag points and build a sense of the team effort that the CIR process requires for continuous improvements to become an integrated part of the culture.

In addition to the dean's understanding of the standards, faculty and staff must "own" the process and participate in creating the report and preparing for the visit. The dean and other administrators then become part of the team, not the ones who "do" accreditation. Key committees, such as the strategic planning committee, can be asked to draft sections of the report identifying their goals, processes and outcomes. Exercises during faculty meetings can generate examples of innovations and outcomes that all can see. Mapping exercises can refresh people's memories of how much has been accomplished during the first-year review cycle and inform those who may be new to the college or board. Cultivating the home team requires building a sense of collaboration and collective knowledge about the story the school is sharing with the PRT team and with AACSB. An annual report may not be an explicit requirement, but preparing an annual report of highlights and sharing that information with key constituents ensures that the program is progressing each year and allows the college to celebrate accomplishments.

Ensuring that the school's home team is ready for the CIR visit is a balancing act. The dean could meet with each group on the agenda to ensure they are prepared for potential questions and ready to engage in a conversation with the PRT. Offering potential questions and practicing key conversation points can reinforce the school's story and build confidence. However, over preparing may scare some, especially students. Ideally, the CIR visit participants will be relaxed, honest and positive in their conversations with the PRT.

These preparatory conversations can be used to engage constituents in continuous improvement conversations, encourage open discussions of issues to be resolved and emphasize the process for improvement.

\section{Plan pre-visit}

A good rule of thumb for any school with a CIR on the horizon is never assume the school is in good shape; get confirmation prior to the visit while there is time for correction and adjustment. Inviting the PRT chair for a pre-visit prior to the CIR visit has become an excellent standard practice for many schools. Including the chair in a pre-visit can help the chair get to know the school and can help faculty and staff feel more comfortable with a familiar face prior to the CIR. Although the CIR report will not be completed at this point, sharing a draft of the report or key sections of the report will be beneficial to the chair. 
The pre-visit should be planned in much the same format as the CIR as follows: identify which groups will meet with the PRT during the CIR (perhaps excluding external partners, students and university administrators), schedule breaks in the agenda and plan all of the details that would be required for any upcoming guest visit (airport pick-up, hotel accommodations, snacks, etc.). All expenses should be covered by the school and as much reimbursement paperwork as possible should be completed before the chair leaves campus to ensure quick processing. With virtual visits becoming the norm, the pre-visit as a virtual connection may make this step easier to complete for the PRT chair and for the school.

Conversations with the team chair should guide how the school prepares the CIR report and visit. Ask the chair about preferred metrics for tables, suggested formats for faculty vita or data sheets and other items to inform the process. Ask the team chair for brutal honesty if he/she sees anything out of the ordinary; it is always better to explain potential weaknesses or concerns in the report than to ignore them and have questions arise during the visit.

Conducting a mock visit with a consultant the year prior to the CIR can provide valuable insight from a completely objective viewpoint and may allow additional time to address weak areas before the pre-visit. The consultant can provide a written debrief identifying both strong and weak points for the school to consider. This feedback should be widely shared with faculty and staff so they can begin to understand the process and see continuous improvement opportunities. Keep in mind, the consultant cannot "guarantee" a positive CIR visit but can offer an opinion for steps to improve. The key focus should remain with the PRT. Many deans do not bring in a consultant and do not have a pre-visit by the chair; these are not required steps. The question for the dean to gauge is the need for objective viewpoints to serve as a continued impetus for change and improvement and the potential increase in the comfort level of the faculty and staff with the upcoming CIR process.

\section{Prepare continuous improvement review report and documentation}

The CIR report should follow AACSB guidelines for format and should cover all required areas including an update of issues identified during the previous visit. The CIR report should be thorough yet succinct. AACSB recommends a 50-page limit for the written report, so spending space on unimportant issues can be as damaging as missing the important ones. Acronyms unfamiliar to external constituents should be kept to a minimum and a table of contents with page numbers are essential so readers can quickly find topics of interest. A well-written CIR report will include key sections that the PRT can easily copy or rephrase for their report (e.g. best practices, assurance of learning successes, impact stories).

Moving toward best practice in preparation of the CIR report requires writing it with multiple audiences in mind. The PRT will be reading the report, but they will also have the option to ask clarifying questions during the visit. Members of the CIRC, however, will rely exclusively on the CIR report and on the PRT's recommendation to assess the school. As the report tells the school's story, it can also be seen as a valuable tool to share components with external constituents (e.g. board members).

All schools have challenges, but the CIR report should be written with a positive tone and a focus on strengths and opportunities. Never hide challenges, but provide readers with information on how the school is dealing with those challenges and planning ways to overcome them. No program is perfect; thus the report should be a road map for highlighting distinctive strengths and plans to improve on challenges.

Diagrams can both simplify school processes and shorten the accompanying text. Key metrics can be summarized in a short table format; for example, readers can get an overview of faculty credentials while reading the text without moving to the detailed tables in the 
OMJ 18,5

report's appendix. Completing the report early enough to have multiple people triple check for typos can help catch errors and engage more people in the process. Submission of the report through AACSB's My Accreditation will also change the dynamics and ability of PRT members to access different areas of interest.

All accompanying materials for the CIR visit should be available before, during and after the visit. Materials should be organized, easily identifiable and legible (i.e. don't use 8-pt type). The list of materials and their locations should be shared with the team and the preferences of each team member should be considered. Comparing documents may be easier done with hard copies than electronic files and some team members may want to read materials if internet access is unavailable. The direction is toward the development of a virtual repository of information with electronic access for the PRT, but the dean should work with the PRT to ensure their needs are met.

In addition to materials AACSB suggests for a CIR visit, the dean should talk with the PRT chair about additional materials the team might find helpful. Some teams may ask to see copies of peer-reviewed journal articles; others may be fine seeing the list of publications without pdf versions of the articles. Materials requested as hard copy should be available in a space such as a work room or a virtual space that is separate from any meeting space during the CIR visit. Copies could be in both the campus work room and a hotel work room for the team to reference as they begin to write their recommendations. Having all materials in a virtual space would enable the team to prepare before the visit and access materials as needed during the visit even when hard copies are not at hand.

\section{Manage the visit}

The CIR visit can be a hectic time for everyone, so prepare for all the details as follows: name tags, campus map if the team will drive in, building floorplan and tour (time permitting), etc. Prepare for team members with limited mobility. The dean should ensure everyone knows where to go and when. A clear agenda is expected; a directory with names and headshots of participants can help team members quickly identify individuals and facilitate conversations. All transitions should be planned in advance, including transportation and parking. Having students escort team members between rooms or buildings can allow the PRT to have casual chats that will reinforce the CIR story. The primary goal during the visit should be "no surprises."

While asking the team members if they have any allergies or food requirements is essential in preparing for the visit, a best practice would be checking with the peer deans' administrative assistants for personal preferences. Welcome the team at the hotel with a basket of snacks. Have drinks and light snacks available in every location throughout the visit and plan for enough for everyone; think of faculty or students who may see snacks in the room without realizing they were intended for the team members. Most CIR visits include a small thank you gift to the team members; this is a wonderful gesture, but keep in mind what the PRT might really use. Few deans would wear a hat with another university's logo back to their home campus.

Regardless of whether the CIR visit is virtual or face-to-face, faculty, staff and students should be active participants, not just part of an audience. Everyone should be fully engaged and for virtual sessions, this means having cameras on. For virtual visits, encourage faculty to log into their sessions a few minutes early and engage with each other in the banter that would be normal for a face-to-face meeting. Often the casual conversations between meetings can be informative for the PRT, so encourage the home team to be themselves humor included! Think of the CIR visit as the opportunity for the school's culture to shine through. 
Though it is understandable to feel the release of pressure when the CIR visit comes to an end, the process is not over. Once the PRT has prepared a draft of their report, the dean should assist by checking for typos or errors. Teams work diligently during the visit, but they may miss or misstate a point and will be grateful for the correction before the report is sent for review by AACSB staff and the CIRC. While the team's recommendation may be shared with internal audiences, it is important to remember that no public statement should be made until the recommendation has been reviewed and approved by the CIRC and ratified by the AACSB Board.

Team members should be reimbursed fully and as quickly as possible after the visit. A heartfelt "thank you" should be sent to the team and to the AACSB staff; their hard work and assistance throughout the process should be acknowledged. Plan for a celebration to thank the home team that spent time and effort to implement a successful CIR visit. Deans who have taken their school through the CIR process are now eligible to serve on a PRT for other schools, so volunteer to serve on a team. This is an excellent way to serve the business school community and to discover innovations and processes to implement at your home school.

True best practice requires remembering that the end of one CIR cycle is the beginning of the next CIR cycle. Document how the school addressed concerns of the PRT and how feedback was incorporated into continuous improvement. Remembering the short tenure of most deans, it is imperative to leave the school in a strong position for the next leadership team and the next CIR visit.

\section{Conclusion}

A successful CIR visit does more than merely check the boxes for a positive recommendation. It builds the story of the school and should be an opportunity for the culture to shine through. This requires moving from the basics of accreditation to understanding, implementing and "living" best practices. The suggestions offered in this article should help schools enhance the long-term positive outcomes and serve as a guide to those navigating the AACSB accreditation process.

\section{References}

AACSB. (2015). What it means to be dean. BizEd, pp. 42-44.

AACSB. (2016). AACSB 2014-2015 deans survey. Retrieved from: www.aacsb.edu/-/media/aacsb/docs/ research/data \% 20downloads/deans-survey-infographic-2014.ashx?la=en

AACSB. (2018). Deans survey 2017-18 infographic. Retrieved from: www.aacsb.edu/-/media/aacsb/ images/charts $\% 20$ and $\% 20$ graphs/data/deans $\% 20$ and $\% 20$ administrators/deans_infographic. ashx?la=en

AACSB. (2019). Continuous improvement review handbook for joint business and accounting. Retrieved from: www.aacsb.edu/accreditation/journey/business/continuous-review

AACSB. (2020a). 2020 Guiding principles and standards for business accreditation. Retrieved from: www.aacsb.edu/-/media/aacsb/docs/accreditation/business/standards-and-tables/2020\%20busin ess \%20accreditation \%20standards.ashx?la=en\&hash=E4B7D8348A6860B3AA9804567F02C68 960281DA2

AACSB. (2020b). 2020 Interpretative guidance for AACSB business accreditation. Retrieved from: www.aacsb.edu/-/media/aacsb/docs/accreditation/business/standards-and-tables/2020\%20interp retive $\% 20$ guidance $\% 20-\% 20$ final $\% 20$ draft $\% 20-\% 20$ july $\% 2023 \% 202020$.ashx?la=en\&hash=DF 488410CBEFBECACD0DB061B226335EDC133D53 
$\mathrm{OMJ}$ 18,5

Bolton, A. (1997). How to succeed in business school leadership by really trying. Perspectives: Policy and Practice in Higher Education, 1(2), 62-65.

Burton, E. J. (2008). Reflections on the challenges of being a dean. In Dhir, K. S. (Ed.), The dean's perspective: Issues in academic leadership in schools of business, pp. 57-62. Atlanta, GA: Decision Sciences Institute.

Chang, Y., Lin, K., \& Tu, T. (2016). The impact of AACSB accreditation on business school students in Taiwan. The Asia-Pacific Education Researcher, 25(4), 615-625. Retrieved from: https://doi-org. wv-o-ursus-proxy02.ursus.maine.edu/10.1007/s40299-016-0289-y doi: 10.1007/s40299-016-0289-y.

Cooper, S., Parkes, C., \& Blewitt, J. (2014). Can accreditation help a leopard change its spots? Social accountability and stakeholder engagement in business schools. Accounting, Auditing \& Accountability Journal, 27(2), 234-258. Retrieved from: https://doi-org.wv-o-ursus-proxy02.ursus. maine.edu/10.1108/AAAJ-07-2012-01062 doi: 10.1108/AAAJ-07-2012-01062.

Desai, V. M. (2016). Third-Party certifications as an organizational performance liability. Journal of Management, 44(8), 3096-3123. Retrieved from: https://doi-org.wv-o-ursus-proxy02.ursus. maine.edu/10.1177/0149206316659112 doi: 10.1177/0149206316659112.

Elliott, C. J. (2013). The impact of AACSB accreditation: a multiple case study of canadian university business schools. Canadian Journal of Administrative Sciences/Revue Canadienne Des Sciences de L'administration, 30(3), 203-218. doi: 10.1002/cjas.1257.

Finch, J. H. \& McIntyre, F. S. (2021). Exit strategies for successful business school deans. Working Paper, University of West Georgia.

Gallos, J. V. (2002). The dean's squeeze: The myths and realities of academic leadership in the Middle. Academy of Management Learning \& Education, 1(2), 174-184. doi: 10.5465/amle.2002.8509367.

Goby, V. P. \& Nickerson, C. (2014). Accreditation and assessment of learning in the UAE. Quality Assurance in Education, 22(3), 212-225. Retrieved from: https://doi-org.wv-o-ursus-proxy02. ursus.maine.edu/10.1108/QAE-05-2013-0023 doi: 10.1108/QAE-05-2013-0023.

Halstead, J. A. (2017). The value of nursing program accreditation. Teaching and Learning in Nursing, 12(3), 181-182. Retrieved from: https://doi.org/10.1016/j.teln.2017.03.005 doi: 10.1016/j.teln.2017.03.005.

MacKenzie, W. I., Jr, Scherer, R. F., Wilkinson, T. J., \& Solomon, N. A. (2019). A systematic review of AACSB international accreditation quality and value research. Journal of Economic and Administrative Sciences, 36(1), 1-15. Retrieved from: https://doi-org.wv-o-ursus-proxy02.ursus. maine.edu/10.1108/JEAS-10-2018-0123 doi: 10.1108/JEAS-10-2018-0123.

Miles, M. P., Franklin, G. M., Grimmer, M., \& Heriot, K. C. (2015). An exploratory study of the perceptions of AACSB international's 2013 accreditation standards. Journal of International Education in Business, 8(1), 2-17. doi: 10.1108/JIEB-02-2014-0009.

Muuka, G. N., Ezumah, B. A., \& Todd, T. (2016). African business schools and the 2013 AACSB accreditation standards: Convergence or crossroads? Academy of Business Journal, 1(1), 46-64.

Prasad, A., Segarra, P., \& Villanueva, C. E. (2019). Academic life under institutional pressures for AACSB accreditation: Insights from faculty members in Mexican business schools. Studies in Higher Education, 44(9), 1605-1618. doi: 10.1080/03075079.2018.1458220.

Romero, E. J. (2008). AACSB accreditation: Addressing faculty concerns. Academy of Management Learning \& Education, 7(2), 245-255. doi: 10.5465/amle.2008.32712622.

Shahzad, S. (2019). Benefits of AACSB international accreditation for SDSB. Lums. Pakistan \& Gulf Economist, 38(14). Retrieved from: https://search.proquest.com/trade-journals/benefits-aacsbinternational-accreditation-sdsb/docview/2343234180/se-2?accountid=15017

Smith, G. E., Barnes, K. J., \& Vaughan, S. (2017). Introduction to the special issue on current issues in AACSB accreditation. Organization Management Journal, 14(1), 2-6. Retrieved from: https://doi. org/10.1080/15416518.2017.1293420 doi: 10.1080/15416518.2017.1293420.

Spritzer, A. D. (2004). It’s not easy being dean. BizEd, pp. 36-40. 
Suárez-Barraza, M., Rodríguez-González, F. G., \& Hart, H. S. (2019). Finding Kaizen core values in AACSB standards accreditation: a conceptual study. Total Quality Management \& Business Excellence, 30(S1), S53-S73. doi: 10.1080/14783363.2019.1665793.

Tomáš, Z. (2017). Accreditation of medical laboratories: System, process, benefits for labs. Journal of Medical Biochemistry, 36(3), 231-237.

Trapnell, J. E. (2007). AACSB international accreditation: the value proposition and a look to the future. Journal of Management Development, 26(1), 67-72. Retrieved from: https://doi-org.wv-o-ursusproxy02.ursus.maine.edu/10.1108/02621710710720112 doi: 10.1108/02621710710720112.

Trapnell, J. E. \& Williams, J. R. (2012). AACSB international: An update and perspective. Issues in Accounting Education, 27(4), 1071-1076. doi: 10.2308/iace-50143.

Urgel, J. (2007). EQUIS accreditation: Value and benefits for international business schools. Journal of Management Development, 26(1), 73-83. doi: 10.1108/02621710710721698.

Widarsyah, R., Ghiselli, R. F., \& Adler, H. (2017). Quality assurance in hospitality and tourism higher education: Administrators' view of ACPHA accreditation - an exploratory study. Journal of Quality Assurance in Hospitality \& Tourism, 18(2), 235-257. doi: 10.1080/1528008X.2016. 1208599 .

Wolverton, M. \& Gonzales, M. J. (2000). Career Paths of Academic Deans., American Educational Research Association Conference, Retrieved from: www.eric.ed.gov/contentdelivery/servlet/ ERICServlet?accno=ED442447

Womack, J. Q. \& Kruger, T. M. (2015). The impact of initial accreditation from AACSB on the enrollment of three South Texas universities. Journal of Business and Behavioral Sciences, 27(1), 158-167.

Zhao, J. \& Ferran, C. (2016). Business school accreditation in the changing global marketplace: a comparative study of the agencies and their competitive strategies. Journal of International Education in Business, 9(1), 52-69. Retrieved from: https://doi-org.wv-o-ursus-proxy02.ursus. maine.edu/10.1108/JIEB-02-2016-0001 doi: 10.1108/JIEB-02-2016-0001.

\section{Corresponding author}

Faye S. McIntyre can be contacted at: fmcintyr@westga.edu

For instructions on how to order reprints of this article, please visit our website: 